\title{
El diagnóstico genético preimplantacional: aspectos jurídicos en el derecho español*
}

\author{
1. Marina Moya González ${ }^{* *}$ \\ 1. Francisca Ramón Fernández ${ }^{* * t}$
}

Resumen. El presente trabajo constituye un análisis sobre el diagnóstico genético preimplantacional (DGP) practicado en España y las leyes que lo regulan. El trabajo, en primer lugar, explica y define el diagnóstico genético preimplantacional, incluyendo una exposición de sus técnicas, los pacientes a quienes va destinado y las consecuencias éticas que este tiene en la sociedad. A continuación se comparan las leyes que regulan la reproducción humana asistida en nuestro país y en algunos países europeos.

Palabras clave: diagnóstico genético preimplantacional (DGP), reproducción humana asistida, legislación española, bioética.

Trabajo realizado en el marco del Proyecto I+D Excelencia MINeco DER2015-6581o-P (201620I8), del Proyecto mineco (Der2013-4256R), y Proyecto del Programa Prometeo para Grupos de Investigación de Excelencia de la Conselleria de Educación, Cultura y Deporte, GVProMETEOII2OI5-OI4.

Fecha de recepción: 26 de septiembre de 2017 . Fecha de aceptación: 22 de enero de 2018.

Para citar el artículo: Moya González, M. y Ramón Fernández, F., "El diagnóstico genético preimplantacional: aspectos jurídicos en el derecho español", Revista de Derecho Privado, Universidad Externado de Colombia, n. ${ }^{\circ}$ 34, enero-junio de 2018, 87-г 2 I.

DoI: https://doi.org/I0.1860I/or 234366.n34.04

* Graduada en Biotecnología. Universitat Politècnica de València, Valencia, España. Contacto: mamogon2@etsiamn.upv.es

*** Doctora en Derecho. Profesora titular de Derecho Civil, Universitat Politècnica de València, Valencia, España. Contacto: frarafer@urb.upv.es 


\section{The Preimplantation Genetic Diagnosis: Legal Aspects in the Spanish Law}

Авstract. This paper analyses the preimplantation genetic diagnosis (PGD) in Spain, and the legal aspects. It exposes the technical characteristics, as well as the ethical and social consequences. It compares the different rules of law about assisted human reproduction techniques in Spain, and those in some European countries.

KeYwords: Preimplantation genetic diagnosis (PGD), assisted human reproduction techniques, Spanish legislation, bioethics.

Sumario. Introducción. I. El DGP: antecedentes y supuestos de aplicación. II. La regulación del DGP en España. III. Principales problemas éticos y jurídicos que plantea el DGP. A. La responsabilidad civil en el DGP. B. La protección de datos de carácter personal en el DGP. C. La prestación del consentimiento en el DGP. D. Sujetos del DGP. E. Elección de características y sexo del preembrión, y DGP. F. El embrión y su consideración jurídica ante el DGP. G. El DGP extensivo. H. DGP y eugenesia. IV. Breve mención a la normativa aplicable al DGP en algunos países europeos. A. Portugal. B. Reino Unido. C. Francia. D. Italia. Conclusiones. Bibliografía.

\section{Introducción}

Con la evolución de la biomedicina se ha mejorado sustancialmente la esperanza de vida, y ello ha sido posible gracias a los avances logrados en los últimos tiempos en la formación, las técnicas y los métodos diagnósticos. Dentro de este campo de investigación, las técnicas de reproducción asistida (TRA) han suscitado un gran interés por la posibilidad de lograr la procreación en supuestos que, hasta ese momento, planteaban numerosas dificultades. La superación de los límites determinados por la esterilidad humana ha hecho de estas técnicas un procedimiento recurrente, aunque no exento de problemas jurídicos. Un ejemplo de la evolución de dichas técnicas para el diagnóstico de enfermedades lo constituye el diagnóstico genético preimplantacional (DGP).

El DGP consiste en la selección de embriones sanos para evitar la transmisión de enfermedades de origen hereditario. Para lograrlo, se utilizan TRA, como la inyección intracitoplasmática de espermatozoides (ICSI) y la fecundación in vitro (FIV).

La introducción de estas técnicas fue necesario un marco legal que estableciera límites para su puesta en práctica. Sin embargo, la existencia de la legislación no ha impedido controversias sociales, éticas y jurídicas, en espera de una nueva regulación que solvente los problemas que plantea la legislación actual. 
Desde un punto de vista histórico, el DGP, como práctica asociada a las TRA, ha sido regulado en España por medio de la siguiente normativa:

a) La primera ley creada fue la Ley 35/1988, de 22 de noviembre, sobre Técnicas de Reproducción Asistida (en adelante, Ley 35/I988). En esta norma, el DGP se permitía en beneficio del propio embrión, pero no se contemplaba el DGP extensivo.

b) Más tarde esta norma fue modificada por la Ley 45/2003, de 2 I de noviembre (en adelante, Ley 45/2003). La reforma no contempló el DGP extensivo.

c) En la actualidad la ley vigente es la Ley I4/2006, de 26 de mayo, sobre Técnicas de Reproducción Humana Asistida (en adelante, Ley i4/2006). Allí se sigue contemplando el DGP en beneficio del propio embrión, y se permite el DGP extensivo.

Desde un punto de vista jurídico, el DGP extensivo plantea una problemática profunda; como se verá más adelante, en el ámbito del derecho comparado se han presentado casos en los que parejas con hijos con enfermedades genéticas graves se han sometido a TRA, en concreto mediante FIV, para tener un descendiente libre del gen enfermo que pueda ser el "hermano/a salvador/a" de su propio/a hermano/a.

La evolución de las TRa ha sido posible, en parte, gracias a las demandas de la sociedad, pues han buscado ofrecer una respuesta adecuada a los deseos de los distintos agentes que intervienen, poniendo el reto para el derecho de establecer criterios que permitan la práctica de estas técnicas, como la responsabilidad de los involucrados, la naturaleza jurídica del embrión, los criterios para el acceso a las TRA y al DGP por parte de los distintos modelos familiares, o para la prestación del consentimiento en las técnicas.

Por tanto, a continuación analizamos algunas cuestiones problemáticas, intentando aportar una perspectiva que pueda orientar el debate entre la comunidad científica, jurídica y política, para que estas técnicas se puedan practicar de la manera más eficaz y segura con respeto de la legislación aplicable.

\section{El DGP: antecedentes y supuestos de aplicación}

En este apartado se estudia el DGP y se presta atención a su evolución histórica, así como a su estado actual, para comprender su aplicación y los distintos problemas jurídicos y sociales derivados del mismo.

El DGP es una técnica que permite detectar y prevenir la transmisión a la descendencia de enfermedades graves causadas por alteraciones genéticas y cromosómicas, mediante el estudio de los embriones antes de su transferencia al útero. Lo anterior gracias a las técnicas de reproducción asistida, ICSI y FIV, que permiten obtener el material biológico para su posterior análisis cromosómico o genético previa implantación. Esto hace posible seleccionar aquellos preembriones libres de carga genética asociada a determinadas enfermedades de distinta índole. 
Se han de distinguir dos conceptos bien diferenciados en relación con el DGP:

- Por un lado, el DGP que, como se indicó anteriormente, analiza la presencia de alelos causantes de la enfermedad del genotipo del embrión, permitiendo descartar aquellos embriones que la presenten antes de ser implantados ${ }^{\mathrm{I}}$.

- Por el otro, el Screening Genético Preimplantacional (sGP), que consiste en seleccionar embriones cromosómicamente normales con el fin de aumentar las tasas de gestación de los ciclos FIV-ICSI, de parejas con mal pronóstico ${ }^{2}$. No obstante, su efectividad no ha sido demostrada, e incluso existen artículos científicos que avalan el efecto negativo de esta técnica ${ }^{3}$.

Los primeros acontecimientos relevantes para el impulso del DGP en el campo de las TRA se remontan a 1952. En dicho año Bevis realiza la primera amniocentesis para el diagnóstico de la eritroblastosis fetal. Es el inicio del diagnóstico prenatal4.

El DGP surge como técnica para identificar posibles enfermedades futuras en la descendencia, evitando con ello futuros problemas que puedan afectar gravemente la salud y el bienestar del nacido. Aunque no ha sido la única técnica, una anterior al DGP es el Diagnóstico Prenatal (en adelante, DP), definido como el conjunto de pruebas diagnósticas realizadas durante el embarazo para intentar identificar la presencia de posibles defectos congénitos en el feto o factores de riesgo maternos que pueden requerir controles estrictos a lo largo de la gestación.

El DGP se puede entender como una forma de DP precoz, con la ventaja de que, tratándose de un diagnóstico previo a la implantación de los embriones, elimina la posibilidad de una eventual interrupción del embarazo, en caso de de-

I Ramos Fuentes, F. y Ribate Molina, M. ${ }^{a}$ P., "Diagnóstico genético preimplantacional" [en línea], Revista Española de Pediatría, n. ${ }^{\circ} 6_{3}(6), 2007$, 443-499, disponible en: http://www.seinap. es/wp-content/uploads/Revista-de-Pediatria/2007/REP\% 2063-6.pdf [Consultado el 22 de septiembre de 2017].

2 Gianaroli, L., Magli, M. C. y Ferrareti, A. P., "The in vivo and in vitro efficiency and efficacy of PGD for aneuploidy" [en línea], Molecular and Cellular Endocrinology, n. ${ }^{\circ}$ г 83, 2001, I 3-г 8, disponible en: http://www.sciencedirect.com/science/journal/03037207/I $83 / \mathrm{supp} / \mathrm{S}_{\mathrm{I}}$ ?sdc=I [Consultado el 25 de septiembre de 20I7].

3 Mastenbroek, S., Twisk, M., Van Echten-Arends, J., Sikkema-Raddatz, B., Korevaar, J. C., Verhoeve, H. R. et al., "In vitro fertilization with preimplantation genetic screening" [en línea], New England fournal of Medicine, n. ${ }^{\circ}$ 357(I), 2007, 9-I 7, disponible en: http://www.nejm.org/ doi/full/IO. IO56/NEJMOaO67744\#t=article [Consultado el 25 de septiembre de 20I 7 ].

4 Díaz Martínez, A. G., Valdés Abreu, M. D. l. C. y Dalmau Díaz, A., "Antecedentes y actualidades en el diagnóstico prenatal" [en línea], Revista Cubana de Obstetricia y Ginecología, 23(I), I997, 25-30, disponible en: http://scielo.sld.cu/scielo.php?script=sci_arttext\&pid=So I 38-600XI 9970 o० I0००० $\& \operatorname{lng}=$ es\&nrm=iso\&tlng=es [Consultado el 25 de septiembre de 201 7]. 
tectar riesgos para el feto, permitiendo evitar secuelas psicológicas en los padres responsables de decidir sobre la vida del feto afectado 5 .

Del año I 990 es la primera noticia que se tenga de gestación mediante DGP ${ }^{6}$. Se trata de las primeras dos gestaciones con éxito, realizadas en Londres usando la metodología del DGP y dando como resultado el nacimiento de dos niñas en cada caso, mediante el sexaje por reacción en cadena de la polimerasa (PCR, por sus siglas en inglés), amplificando una secuencia específica del cromosoma Y. Al tratarse de enfermedades ligadas al sexo al inicio de la técnica resulta un buen método para evitar el nacimiento de hijos afectados por la enfermedad.

En España, en 1994 se produce el primer nacimiento con $\mathrm{DGP}^{7}$. El primer embarazo de DGP conseguido en este país se realizó en colaboración entre la Universitat Autónoma de Barcelona (UAB) y el Instituto Universitario Dexeus. Se trata de la utilización de esta técnica con miras a evitar la aparición de enfermedades ligadas al sexo, lo que hace del DGP un buen método para evitar el nacimiento de hijos afectados por la enfermedad. Como resultado se obtuvo el nacimiento de dos niñas sanas.

Las técnicas de inseminación empleadas en estos casos son la FIV y la ICSI, dependiendo de las particularidades de los pacientes, como se ha indicado anteriormente.

En lo que respecta a las indicaciones, se trata de la técnica del DGP aplicable a la gestación de embriones sanos, procedentes de parejas portadoras de enfermedades genéticas, o alteraciones de origen genético. El diagnóstico permite la selección de embriones que no tengan los genes portadores de la enfermedad.

Existen genes que son portadores de determinadas enfermedades, lo que provoca que aquellas personas que los poseen puedan sufrir esta enfermedad, y a su vez existe el riesgo de que lo transmitan a su descendencia. Es el caso de determinados tipos de cáncer, malformaciones, o de la neurofibromatosis.

Se ha permitido el proceso en los casos de anomalías cromosómicas numéricas o estructurales, que comportan un alto riesgo de infertilidad y transferencia de enfermedades. Dentro de las anomalías cromosómicas encontramos ${ }^{8}$ las

5 Lloveras N. y Sapena J., "El Diagnóstico Genético Preimplantacional” [en línea], Bioética y Derecho, n. ${ }^{\circ}$ I8, 20го, Iо-I6, disponible en: http://revistes.ub.edu/index.php/RBD/article/ view/798I/9883 [Consultado el 24 de septiembre de 201 7].

6 Handyside, A. H., Kontogianni, E. H., Hardy, K. y Winston, R. M. L., "Pregnancies from biopsied human preimplantation embryos sexed by Y-specific DNA amplification" [en línea], Nature, n. ${ }^{\circ}$ 344, I990, 768-770, disponible en: https://www.nature.com/scitable/content/Pregnancies-from-biopsied-human-preimplantation-embryos-sexed-I I575 [Consultado el 22 de septiembre de 20I7].

7 Veiga, A., Santaló, J., Vidal, F., Calderón, G., Giménez, C., Boada, M., Egozcue, J. y Barri, P. N., "Twin pregnancy after preimplantation diagnosis for sex selection: Case report", Human Reproduction, n. ${ }^{\circ}$ 9, I994, 2 I 56-2 I 59.

8 Muñoz-Núñez, M., Girón, J., Molina, L., Fernández, L., Velarde, P., Figueroa, M. J. y González, A., "Enfermedades hereditarias y técnicas de detección preimplantacionales" [en 
anomalías numéricas o aneuploidías; las anomalías estructurales, entre las que se encuentran las translocaciones cromosómicas, recíprocas, robertsonianas, deleciones, duplicaciones, inserciones e inversión9.

También ha sido consentido en el caso de enfermedades ligadas a cromosomas sexuales, ya que existen enfermedades ligadas tanto al cromosoma $\mathrm{X}$ como al cromosoma Y. En estos casos se suele optar por un diagnóstico genético preimplantacional, por el cual se escoge el sexo del embrión, empleando los métodos de diagnóstico de hibridación genómica comparada (CGH-array) ${ }^{\mathrm{IO}}$ e hibridación in situ fluorescente (FISH). La selección del sexo está permitida solo cuando implique el beneficio de evitar padecer la enfermedad. Hay distintas variables de transmisión, y dependiendo de ellas se escogerá entre sexo femenino y mascu$\operatorname{lino}^{\mathrm{II}}$.

Así mismo, se ha permitido en el caso de enfermedades monogénicas, ya que en estos casos la afección aparece cuando un progenitor contiene en su genoma una severa perturbación, producida por la mutación de un gen concreto; algunos ejemplos de estas enfermedades son la atrofia muscular espinal, la distrofia miotónica y algunos tipos de cáncer como el de mama. Estas enfermedades se pueden presentar por dos tipos o categorías: el tipo dominante y el tipo recesivo. La técnica utilizada para detectar estas enfermedades suele ser la reacción en

línea], Revista Iberoamericana de Fertilidad, n. ${ }^{\circ}$ 22, 2005, 343-359, disponible en: http://www. revistafertilidad.org/RecursosweB/fertilidad/Fert-Sept-Octo5-Trabajo7-pdf [Consultado el 20 de septiembre de 2017].

9 Scriven, P. N., Handyside, A. H. y Ogilvie, C. M., "Chromosome translocations: Segregation modes and strategies for preimplantation genetic diagnosis", Prenatal Diagnosis, n. ${ }^{\circ}$ I8(1 13 ), i 998, i437-I 449; Bell, K. A., van Deerlin, P. G., Feinberg, R. F., du Manoir, S. y Haddad, B. R., "Diagnosis of aneuploidy in archival, paraffin-embedded pregnancy-loss tissues by comparative genomic hybridization" [en línea], Fertility and Sterility, n. ${ }^{\circ}$ 75(2), 200 I, 374-379, disponible en: http://www.fertstert.org/article/Soo 1 5-0282(o0)o 1 703-9/pdf [Consultado el ig de septiembre de 20i 7]; Ballif, B. C., Kashork, C. D., Saleki, R., Rorem, E., Sundin, K., BejJani, B. A. y Shaffer, L. G., "Detecting sex chromosome anomalies and common triploidies in products of conception by array-based comparative genomic hybridization", Prenatal Diagnosis, n. ${ }^{\circ}$ 26(4), 2006, 333-339.

io De Los Ángeles Mori, M., Mansilla, E., García-Santiago, F., Vallespín, E., Palomares, M., Martín, R. y Lapunzina, P., "Diagnóstico prenatal y array-hibridación genómica comparada (CGH)(I). Gestaciones de elevado riesgo" [en línea], Diagnóstico Prenatal, n. ${ }^{\circ} 23(2), 2012$, 34-48, disponible en: http://www.elsevier.es/es-revista-diagnostico-prenatal-327-articulo-diagnostico-prenatal-array-hibridacion-genomica-comparada-S2 I 734I27I2000339 [Consultado el I9 de septiembre de 20I7]; Cheng, L., Zhang, S., Wang, L., Maclennan, G. T. y Davidson, D. D., "Fluorescence in situ hybridization in surgical pathology: Principles and applications" [en línea], The fournal of Pathology: Clinical Research, n. ${ }^{\circ}$ 3, $2017,73-99$, disponible en: http://onlinelibrary.wiley.com/doi/ro.1002/cjp2.64/epdf [Consultado el I9 de septiembre de 20I 7]; Jobanputra, V., Roy, K. K. y Kucheria, K., "Prenatal detection of aneuploidies using fluorescencein situ hybridization: A preliminary experience in an Indian set up" [en línea], Fournal of Biosciences, n. ${ }^{\circ} 27$ (2), 2002, I 55-163, disponible en: http://www.ias.ac.in/article/fulltext/jbsc/O27/O2/OI 55Or63 [Consultado el 25 de septiembre de 20I7].

i i Muñoz-Núñez, Girón, Molina, Fernández, Velarde, Figueroa y González, "Enfermedades hereditarias y técnicas de detección preimplantacionales", cit., 345 . 
cadena de la polimerasa (PCR), la cual permite detectar la mutación genética que ocasiona problemas en su descendencia ${ }^{\mathrm{I} 2}$.

Por ello es recomendable la utilización del DGP por parte de parejas o madres que se encuentran en programas de fecundación in vitro, que hayan sufrido varios abortos, o con un número repetido de fallos en implantaciones, también aquellas madres con edades superiores a los treinta y siete años, y los padres con meiosis masculina alterada. El DGP puede ayudarles mediante la selección de aquellos cromosomas causantes de problemas, antes de la fecundación del útero, permitiendo incrementar la posibilidad de concebir y disminuyendo los abortos $^{13}$.

El DGP está indicado también en los supuestos de enfermedades hereditarias de surgimiento tardío, porque previene la herencia de enfermedades no manifestadas en los progenitores, y su diagnóstico es reservado. Existen parejas o madres que deciden tratar a su descendencia sin saber si son portadores. Esta excepción permite realizar una fecundación in vitro, pero sin que los padres sepan si son portadores.

Por último, está también permitido el llamado DGP extensivo, es decir, cuando el beneficiario de una eventual terapia es una tercera persona, como es el caso de los hermanos. Se trata del denominado diagnóstico genético preimplantacional con finalidad terapéutica a favor de terceros (en adelante DGP-HLA), también conocido como DGP extensivo ${ }^{\mathrm{I}}$.

Esta excepción queda regulada por la Ley I4/2006, en la cual se permite la aplicación de este proceso para seleccionar los antígenos de histocompatibilidad, con la intención de ayudar a terceros.

Estos son los casos en los cuales es recomendable realizar el DGP, con el fin de seleccionar aquellos embriones que cumplan las características genéticas más óptimas. En España solo está permitida la selección por motivos de salud, nunca por razones sociales.

En algunos casos, para poder realizar el DGP será necesario, en primer lugar, un informe favorable de la Comisión Nacional de Reproducción Asistida, y posteriormente este informe será presentado ante la autoridad sanitaria pertinente, la cual deberá dar su autorización.

I2 Renwick, P. y Ogilvie, C. M., "Preimplantation genetic diagnosis for monogenic diseases: Overview and emerging issues" [en línea], Expert Review of Molecular Diagnostics, n. ${ }^{\circ}$ 7(I), 2007 , 33-43, disponible en: http://www.tandfonline.com/doi/full/ıo. I 586/I4737 I 59.7.I.33 [Consultado el i9 de septiembre de 20I7].

i Mercado, C. A., Pedrueza, J. R. y García Ercoli, S. A., "dgr: técnica e indicaciones”, Revista Médica Tucumán, I 5(1), 2010, 22-38.

i4 Enguer Gosálbez, P. y Ramón Fernández, F., "Dilemas bioéticos y jurídicos de la reproducción asistida en la sociedad actual en España” [en línea], Revista Latinoamericana de Bioética, n. ${ }^{\circ}$ 34, 20 I 8, disponible en: https://revistas.unimilitar.edu.co/index.php/rlbi/article/view/3 I60 [Consultado el 7 de diciembre de 20I7]. 


\section{La regulación del DGP en España}

Llegados a este punto interesa estudiar las diferentes leyes que han existido en España acerca del DGP: Ley 35/1988; Ley 45/2003, que modifica la anterior, y Ley I $4 / 2006$. Estas leyes no regulan de forma individualizada el DGP sino que engloban otros aspectos de las técnicas de reproducción asistida (TRA), que también se tendrán en cuenta para hacer notoria la evolución tanto de las leyes como de la sociedad, con respecto a la reproducción asistida (RA).

En España, la regulación inicial por la Ley 35/1988 se ha visto superada por las normas posteriores, cada una de las cuales ha ido sustituyendo a la anterior debido a la demanda de renovación implícita en los años, ya que las TRA, como otros avances científico-técnicos, se encuentran en auge y sus legislaciones van quedando obsoletas.

A continuación se desglosan las características de estas leyes, a fin de evaluar sus similitudes y diferencias, así como posibles defectos en su aplicación.

Los avances científicos realizados en los campos de la biotecnología y la biomedicina en los años 70 determinaron el auge de las TRA, lo que llevó a la necesidad paralela de regular tales progresos, de donde surge la citada Ley 35/r988.

Esta ley permaneció vigente durante varios años, en parte debido a la permisividad que ofrecía entonces, y en ella se hace referencia a una serie de puntos básicos:

- Se establece el listado cerrado de TRA permitidas por la ley.

- Se prohíbe la fecundación de óvulos con fines distintos a la procreación; por tanto, no se generarán embriones de forma deliberada para investigación.

- El número de embriones a transferir y fecundar queda abierto a las consideraciones médicas.

- Se permite la donación de gametos.

- La procreación post mortem solo es válida en el caso de que el varón haya dado previamente su consentimiento en escritura pública o testamento y de que se produzca seis meses después de su fallecimiento.

- La criopreservación de gametos es de 5 años en el caso del semen y no es autorizada en el caso de óvulos si no se garantiza su viabilidad tras descongelación.

- La crioconservación de los preembriones es admitida por un máximo de 5 años en un banco autorizado; y pasados 2 años, aquellos no procedentes de donantes pasarán a disposición del propio banco.

- En cuanto al diagnóstico de anomalías en el preembrión o feto, se aprueba en tanto que se realice en beneficio del propio embrión. No se menciona el DGP extensivo.

- La investigación con gametos se admite en experimentación básica y experimental.

- La investigación con preembriones se encuentra restringida, ya que aquellos considerados no viables quedan limitados a que exista consentimiento por 
parte de las personas de las que proceden, a que no se desarrollen más de I4 días y a que no pueda realizarse en modelos animales. Sin embargo, los preembriones viables solo se podrían usar en investigación cuando generen una ventaja para el propio embrión.

- El destino de los preembriones a elección de las personas de las que provienen puede ser muy diverso: mantenerlos hasta transferencia, donarlos para fines reproductivos, destinarlos a investigación o descongelarlos.

- Se prohíbe tanto la selección del sexo como la gestación subrogada y la clonación.

$\mathrm{Al}$ tratarse de la primera ley que reguló la reproducción asistida, supuso una gran polémica, ya que la reproducción envuelve a diversos colectivos, no siendo una cuestión individual sino social. La ley supuso un aval y un marco jurídico para las TRA y para todas las personas involucradas en el proceso (médicos, progenitores, donantes, sin olvidar la determinación de un estatuto para el embrión y futuro nacido). En estos años, el hecho de que una mujer no casada pudiera acceder a las técnicas fue muy comentado. Del mismo modo, en una sociedad donde la paternidad legal y la biológica se entendían como iguales, el hecho de establecer el anonimato de los donantes y la posibilidad de distintos modelos familiares supuso un gran adelanto, no obstante lo cual fue rechazado por determinados sectores ${ }^{15}$.

Por otro lado, el DGP como se contempló dentro de la Ley 35/1988, mencionado en el artículo 4 apartado 2, también fue objeto de crítica. Uno de los principales puntos discutidos fue la calificación como sujeto respecto del diagnosticado, tanto por el hecho de que se genera artificialmente como por su "edad". El inconveniente surge cuando se cuestiona la existencia de diferencias biológicas entre el generado artificialmente y el natural que puedan justificar un trato jurídico distinto. Finalmente, pese a la problemática originada, el DGP se consolidó como un método diagnóstico capaz de evitar el implante de preembriones afectados por las enfermedades testadas. Su aprobación comportó en muchos casos la sustitución del aborto (pues eliminando el riesgo de enfermedades genéticas, ya no habría necesidad de abortar por dicha causa) ${ }^{16}$.

Esta norma se vio modificada por el Real Decreto 906/2007, de 6 de julio, y posteriormente por el Real Decreto 42/2010, de I 5 de enero, por el que se regula la Comisión Nacional de Reproducción Humana Asistida. La función de este organismo es la de asesorar y responder a las consultas del Gobierno a

I 5 CASADo, M., "Reproducción humana asistida: los problemas que suscita desde la bioética y el derecho" [en línea], Papers: Revista de Sociología, n. ${ }^{\circ}$ 53, 1997, 37-44, disponible en: http://papers. uab.cat/article/view/v53-casado/pdf-es [Consultado el 25 de septiembre de 2017].

i6 Díaz de Terán Velasco, M. C., "El diagnóstico preimplantatorio en la ley 35/i 988, de 22 noviembre, sobre técnicas de reproducción asistida" [en línea], Derecho y Salud, n. ${ }^{\circ}$ I I, 2003, 73-84, disponible en: http://dadun.unav.edu/bitstream/Ior7I/I3428/I/diazdet_diagnos_preimplantatorio.pdf [Consultado el 25 de septiembre de 2017]. 
fin de recopilar y actualizar los conocimientos científicos relacionados con las TRA, así como regular los centros de reproducción asistida para su mejor uso. Esta norma se vio modificada por el Real Decreto 906/2007, de 6 de julio, por el que se modifica el Real Decreto 4I 5/I997, de 2 I de marzo, que crea la Comisión Nacional de Reproducción Humana Asistida, y posteriormente por el Real Decreto 42/2010, de 15 de enero, por el que se regula la Comisión Nacional de Reproducción Humana Asistida.

Tras I 5 años de vigencia de la Ley 35/r 988 se advirtieron limitaciones en la norma debidas a los avances en la técnica. Concretamente, en dos artículos de la anterior ley: los artículos 4 y I I, que hacen referencia al número de preembriones transferibles al útero y a la criopreservación respectivamente. La modificación de la ley fue propuesta por la Comisión Nacional de Reproducción Humana Asistida (CNRHA) y el Comité Asesor de Ética en Investigación Científica y Tecnológica (CAEICT).

En el artículo 4 de la presente ley se estandariza en 3 el número total de preembriones transferibles al útero de una mujer en cada ciclo. Con ello se restringe la libertad de decisión contemplada por la anterior normativa. Este cambio se propone para evitar embarazos múltiples que puedan dañar la salud de la madre.

En cuanto al artículo I I, su principal objetivo es sortear la generación y acumulación de embriones supernumerarios. De este modo se aumentó el tiempo en que los espermatozoides y preembriones podían mantenerse criopreservados, a toda la vida del donante. También contempla la criopreservación de óvulos que aparecía muy restringida en la anterior ley.

Los problemas que esta nueva legislación conlleva al ser aplicada son ${ }^{\mathrm{1}}$ :

I. Establecer el límite máximo de 3 embriones transferibles no implica una mejora de la tasa de gestación, pero sí aumenta la tasa de gestaciones múltiples.

II. Limitar a 3 el número de ovocitos a fecundar supuso una descenso en el rendimiento de las TRA, puesto que no es lo mismo elegir los 3 embriones a transferir que disponer solo de los 3 que se deben transferir. Además, genera problemas dentro del planteamiento de la técnica de DGP, puesto que requiere de un número de embriones mínimo para poder asegurar la calidad final de aquellos a transferir.

Por esta razón se promulgó el Real Decreto I 720/2004 por el que se establecen las excepciones fisiopatológicas que deben sufrir los progenitores y que eximen del obligado cumplimiento al artículo 4 apartado $3^{[18]}$.

I 7 Molina, I., Duque, C. C. y Alfonso, J., "Controversias legales en reproducción asistida humana", Revista Iberoamericana de Fertilidad, n. ${ }^{\circ}$ 23, 2006, 63-70.

I 8 Boada, M., "La reproducción asistida. Problemática actual", Revista de Debate Politico, Fundación Rafael Campalans, n. ${ }^{\circ}$ 9, 2004, I-9. 
III. No permitir fecundar más de 3 ovocitos y que este número sea a su vez el adecuado para transferir al útero hace que el problema de almacenamiento de embriones se solvente. Sin embargo, en aquellos casos en que se quisiera repetir la TRA, ya hubiera sido exitosa o no, se requería el volver a someterse a todo el proceso de nuevo.

IV. Se genera una contradicción al consagrar una legislación más laxa en relación con la destinación de los preembriones generados con anterioridad a la Ley 45/2003 para la investigación científica. Los que se generen con posterioridad solo pueden usarse con fines reproductivos de la pareja o ser donados para su fecundación.

v. Otro problema surge con el consentimiento que debe firmarse por parte de ambos progenitores en cuanto al destino de sus embriones, pudiendo ser muy diferente: mantenerlos hasta transferencia, donarlos para fines reproductivos, destinarlos a investigación o descongelarlos. Si no existe consenso o cada progenitor elige un destino diferente, la resolución de este inconveniente generaría una gran controversia al existir la posibilidad de dividir estos embriones para finalidades distintas. La complicación aumenta si tenemos en cuenta que los embriones se conservan en el mismo envase criogénico.

En el resto de articulado la ley no se ve alterada; es por ello que el CNRHA no tardó en proponer otra legislación más completa que solventase las limitaciones explicadas.

La evolución de la reproducción asistida no se ha detenido en los últimos años, por este motivo se hizo necesario el establecimiento de una nueva normativa que se ajustara más a los progresos científicos logrados.

Por ello, las reformas posteriores reafirman el papel de la Comisión Nacional de Reproducción Humana Asistida, cuyas funciones, aparte de las citadas anteriormente, serán las de aplicación de las técnicas de diagnóstico preimplantacional, especialmente en el caso de DGP extensivo, donde se precisa de autorización y estudio de cada caso por parte del centro sanitario donde se llevará a cabo la TRA y por parte de la CNRHA.

Además de la legislación señalada hasta ahora, existen otras normativas que, pese a no estar relacionadas con la RA, sí lo están con el DGP, pues aunque no lo regulen directamente, sí se refieren a la metodología que emplea.

Es el caso, por ejemplo, de la Ley 42/ I 988, de 28 de diciembre, de donación y utilización de embriones y fetos humanos o de sus células, tejidos u órganos. Esta ley se promulgó con posterioridad a la Ley 35/r988, en la que ya se mencionaba al diagnóstico prenatal como posible técnica aceptada, y regula la donación y uso de embriones y fetos para fines no reproductivos, dentro de los cuales incluimos los fines diagnósticos como el DGP. Así, se establece que la extracción de células o tejidos de embriones, fetos, placenta, envolturas y líquido amniótico puede hacerse exclusivamente con fines diagnósticos. Además, establece que la tecnología genética pueda usarse en este diagnóstico, in vitro o in vivo, para 
detectar enfermedades genéticas o hereditarias, para evitar su transmisión, para tratarlas o curarlas.

También se tiene la Ley I4/2007, de 3 de julio, de investigación biomédica. El objeto de la ley es la regulación de los procedimientos en investigación biomédica que impliquen métodos invasivos para asegurar la dignidad e identidad humana y los derechos inherentes a la persona. En esta normativa se contempla al Comité de Bioética como organismo regulador que proporcione mecanismos de fomento, divulgación y coordinación científica. En lo que respecta al DGP, no se lo menciona directamente, pero sí se hace alusión al tratamiento de muestras biológicas y su almacenamiento, así como a la donación y utilización de ovocitos, espermatozoides, preembriones, embriones y fetos humanos o de sus células, tejidos u órganos con fines de investigación biomédica y sus posibles aplicaciones clínicas. Esto debe de tenerse en cuenta a la hora de operar con las muestras de un DGP y también con los resultados confidenciales genéticos que deriven de sus resultados.

Por último, se tiene la Orden ssi/2065/20I4, de 3 I de octubre, por la que se modifican los anexos I, II y III del Real Decreto I030/2006, de I 5 de septiembre, por el que se establece la cartera de servicios comunes del Servicio Nacional de Salud (sNs y el procedimiento para su actualización.

En lo referido al DGP, se lo incluye dentro de la cartera de servicios del sNS y por tanto las administraciones sanitarias deben reembolsar los gastos que deriven de él. Es la primera vez que el DGP se incluye dentro del sNs, entendida como una técnica de índole preventiva y terapéutica.

\section{Principales problemas éticos y jurídicos que plantea el DGP}

A continuación se analizará la normativa actual vigente referente a las TRA, con el fin de evaluar los problemas bioéticos y jurídicos que se plantean en el caso del DGP, tanto en el ámbito de la responsabilidad como del error en el diagnóstico, los problemas éticos y sociales, así como la naturaleza del embrión.

Uno de los principales objetivos de la bioética es la protección del ser humano, siguiendo las directrices marcadas por los artículos I y siguientes del "Convenio para la protección de los derechos humanos y la dignidad del ser humano con respecto a las aplicaciones de la Biología y la Medicina”, también llamado "Convenio de Oviedo", de 4 de abril de I $997^{[\text {[19]. }}$

I9 Convenio para la Protección de los Derechos Humanos y la Dignidad del Ser Humano con respecto a las Aplicaciones de la Biología y la Medicina [en línea], disponible en: http://www. codem.es/Adjuntos/codem/Documentos/Informaciones/Publico/fo44efef-58a7-4oe4-bb7b-

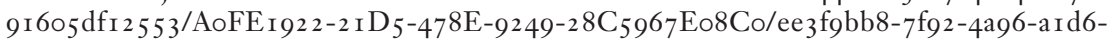
67Ifgofbd838/ee3fgbb8-7f92-4a96-a Id6-67 If gofbd838.pdf [Consultado el 8 de diciembre de 2017]. 


\section{A. La responsabilidad civil en el DGP}

El centro médico donde se practique la TRA debe conocer y hacer cumplir la normativa vigente, asegurando ciertos principios de garantía de los derechos del paciente, como la necesidad de su opinión, la aceptación del procedimiento y la privacidad. En el caso del DGP habrá que tener presente que al involucrar más de un paciente, las decisiones de cualquiera de ellos no pueden causar perjuicios a los demás, y en caso de que se presenten, surgirá la responsabilidad civil del centro médico o profesional ${ }^{20}$.

La Ley I4/2006 contempla en los artículos 4, I7 y i8 los marcos legales que conciernen a los requisitos y responsabilidades solicitados por el centro de aplicación ${ }^{21}$. Se precisa que las prácticas de reproducción asistida han de ser realizadas por parte de centros autorizados, con equipos debidamente cualificados, y que incurrirán en responsabilidad tanto los equipos biomédicos como la dirección de los centros prestadores de servicios en los casos de violación del secreto de la identidad de los donantes, realización de malas prácticas con las TRA, o si por omisión de la información o estudios se lesionan los intereses de donantes o usuarios o se transmiten a los descendientes enfermedades congénitas o hereditarias que se hubieran podido evitar con la información y estudio previo.

La responsabilidad prevista en el artículo I 8.2 de la Ley I $4 / 2006$ ha planteado distintos aspectos problemáticos, que la doctrina se ha ocupado de resolver ${ }^{22}$ :

a) El precepto es calificado como defectuoso e incompleto, ya que no recoge todas las conductas u omisiones que pueden dar lugar a responsabilidad civil.

b) La naturaleza de los daños producidos, que podrán ser patrimoniales o extrapatrimoniales. Es necesario diferenciar los daños producidos por las TRA de los que se pueden producir durante el embarazo, que pueden tener origen en una negligencia médica o violación de la lex artis ad hoc.

20 Rodríguez-Cadilla Ponce, M. D. R., "Consideraciones bioéticas y jurídicas de la información genética y el diagnóstico prenatal” [en línea], Vox furis, 28(2), 2014, I 5-40, disponible en: http:// www.aulavirtualusmp.pe/ojs/index.php/VJ/article/view/6/7 [Consultado el 25 de septiembre de 2017$]$.

2 I Véase Fernández González, M. ${ }^{a}$ B., "La responsabilidad civil del médico: su incidencia en las técnicas de reproducción asistida", Actualidad Civil, n. ${ }^{4}$, I997, I073-ı088; Asúa González, C. I., "Responsabilidad civil derivada del uso de técnicas de reproducción asistida", en Díaz Martínez, A. (coord.), Régimen jurídico-privado de la reproducción asistida en España: el proceso legal de reformas, Madrid, Dykinson, 2006, I03-I 20; Pinto Andrade, C., "La responsabilidad civil médico sanitaria derivada de las Técnicas de Reproducción Asistida”, Revista Aranzadi de Derecho Patrimonial, n. ${ }^{\circ}$ 23, 2009, I 27-I 55.

22 Seguimos a Díaz Martínez, A., "Responsabilidad por daños en la aplicación de técnicas de reproducción asistida: diferencias con la investigación biomédica (a propósito de las ssts de 23 de octubre de 2008 y 20 de noviembre de 2009)" [en línea], Revista de Derecho y Genoma Humano, n. ${ }^{\circ}$ 32, 2010, I93-2 I 8, disponible en: https://mega.nz/\#!Sdkleblr!consys4e6rlGFkqxhWGgL GPoZagJkgR_LUk3 3 f5gNlA [Consultado el 8 de diciembre de 20 I 7]. 
c) La naturaleza de la responsabilidad no es clara: si es contractual se aplicaría el artículo i io r c.c., si es extracontractual, derivada de una violación al principio de neminem laedere, corresponde aplicar el artículo I 902 c.c., y resolviéndose por los tribunales por la aplicación de la yuxtaposición de responsabilidades.

El artículo 25 de la Ley I4/2006 establece la responsabilidad por la autoría en el caso de que se cometa, por acción u omisión, alguna de las infracciones (leves, graves y muy graves) establecidas en los artículos 26 y siguientes, además de las que se puedan contemplar en la Ley I4/ı986, de 25 de abril, General de Sanidad, junto con los delitos o faltas contemplados en la Ley Orgánica Io/ı995, de 23 de noviembre, del código penal.

En el caso de que el cumplimiento de las obligaciones previstas en la Ley I 4/2006 corresponda a varias personas conjuntamente, la responsabilidad será solidaria y no subsidiaria respecto de las infracciones y sanciones.

Los directores de los centros o servicios también tendrán responsabilidad de carácter solidario respecto de las infracciones que cometan los equipos biomédicos que dependan de ellos, según lo que indica la Ley 39/20 I 5, de I de octubre, del procedimiento administrativo común de las administraciones públicas.

\section{B. La protección de datos de carácter personal en el DGP}

A la hora de someternos a cualquier asunto o proceso sanitario, del cual se extraigan datos e información de ámbito privado y personal, debemos contar con la seguridad de que la legislación ampara la protección de los mismos, impidiendo el manejo de información privada sanitaria por personas no cualificadas ni autorizadas. Es por ello que los datos obtenidos de técnicas como el DGP deben garantizar un uso confidencial de los datos.

Con el DGP se extrae información detallada sobre posibles alteraciones genéticas de progenitores e hijos. Por ello la preocupación radica en que los datos privados genéticos sean utilizados por otras personas que usen esta información para su propio beneficio. Por esta razón se precisa del amparo legal que evite el abuso de tal información. Sin embargo, existe la posibilidad de cesión de datos, siempre y cuando se preste consentimiento expreso y escrito del paciente ${ }^{23}$.

La normativa que regula la confidencialidad de datos se recoge en la Ley Orgánica I5/1999, de I3 de diciembre, de Protección de Datos de Carácter Personal, y en el Real Decreto I 720/2007, de 2 I de diciembre, Reglamento de desarrollo de la anterior.

En los últimos años se ha promovido una regulación más uniforme del derecho fundamental a la protección de datos en el marco de una sociedad cada vez más globalizada, aceptándose un Anteproyecto de la nueva ley de protección de

23 Rodríguez-Cadilla Ponce, "Consideraciones bioéticas y jurídicas de la información genética y el diagnóstico prenatal", cit., 36 . 
datos de carácter personal, que entrará en vigor a partir del 25 de mayo de 20 I 8 , tras la aprobación del Reglamento (UE) 2016/679 del Parlamento Europeo y del Consejo de 27 de abril de 20 i 6 relativo a la protección de las personas físicas en lo que respecta al tratamiento de datos personales y a la libre circulación de estos datos y por el que se deroga la Directiva 95/46/CE (Reglamento general de protección de datos).

En esta normativa se establece la protección de datos personales, especialmente en lo que concierne al honor personal y familiar. No obstante, estos datos personales podrán ser utilizados por profesionales sanitarios siempre y cuando se precisen para el diagnóstico, prevención o tratamiento médico, ateniéndose al secreto profesional y confidencialidad médico-paciente, o incluso por otras personas que, del mismo modo, están sujetas a la misma obligación de secreto. En la disposición adicional sexta de la Ley Orgánica I 5/I 999 se estipula que "los datos relativos a la salud sólo podrán ser objeto de tratamiento con el consentimiento expreso del afectado".

En el ya citado Convenio de Oviedo se confirman estas previsiones en el artículo ro referido a la vida privada y el derecho a la información. Además, queda establecido el derecho a no ser informado cuando esta sea la voluntad del paciente.

\section{La prestación del consentimiento en el DGP}

Como establece la Ley I4/2006, toda persona que se someta a una TRA, entre las que se encuentra el DGP, debe estar perfectamente informada por el médico o profesional competente, a fin de establecer una comunicación clara, concisa y entendible por los pacientes. Se debe informar de los riesgos, las consecuencias de la anomalía, las probabilidades de transmisión de la enfermedad, los beneficios, las probabilidades de evitarla y los procedimientos a los que deben some$\operatorname{terse}^{24}$.

La aplicación de las técnicas de DGP, al igual que todos los procedimientos científicos, debe seguir unas normas morales y éticas. En el Informe Belmont se desarrollaron los llamados Principios de la Bioética, a fin de estandarizar y fijar un manual básico con estas pautas:

I. Justicia. Establece la equidad de beneficios y riesgos sin lugar a preferencias ni a crear desventajas fundadas en la capacidad económica o el estatus social.

II. Autonomía. Se refiere a la toma de decisión libre e informada por parte del paciente tras conocer tanto los riesgos como las ventajas. Este principio está

24 Matorras, R. y Hernández, J. (eds.), Estudio y tratamiento de la pareja estéril: recomendaciones de la Sociedad Española de Fertilidad, con la colaboración de la Asociación Española para el Estudio de la Biología de la Reproducción, de la Asociación Española de Andrología y de la Sociedad Española de Contracepción [en línea], Madrid, 2007, 33 I-346, disponible en: http://www.sefertilidad.net/docs/ biblioteca/recomendaciones/completo.pdf [Consultado el 23 de septiembre de 20 I 7 ]. 
relacionado con la obligación de dar un consentimiento libre e informado, ya que se debe velar por que cualquier persona que quiera ser sometida a un procedimiento sanitario esté en condiciones de valorar, con toda la información necesaria previamente explicada, si realmente quiere someterse a la técnica.

III. Beneficencia. Alude a que la ciencia debe ir encaminada a proporcionar un beneficio o evitar un daño. La beneficencia prevalece sobre la autonomía en aquellos casos donde no pueda ejercitarse.

Iv. No maleficencia. Comporta el deber de impedir la provocación de dolor tanto por omisión como de manera intencionada. Este principio se relaciona con los fallos causados por la falta de formación.

Tanto en la ley vigente sobre tra como en el Convenio de Oviedo es objeto de especial atención el consentimiento de personas que no pueden prestarlo. En los artículos 6 y 7 se estipula la necesidad de trasladar la toma de decisión a un representante cuando la persona no pueda dar su consentimiento debido a trastornos mentales, minoría de edad u otras causas que lo impidan, teniendo siempre en cuenta las consideraciones del paciente y que la decisión tenga como objetivo su beneficio. En el artículo 8, que menciona las situaciones de urgencia, se establece que no será necesario el consentimiento cuando ello derive en favor de la salud del paciente. Además, todo deseo expresado con anterioridad deberá ser tenido en cuenta, como señala el artículo 9. Por tanto, se extrae la conclusión de que el principio de beneficencia prevalece sobre el de autonomía, ya que se precisa de garantías en favor de la salud del paciente para aplicar cualquier técnica.

\section{Sujetos del DGP}

En los siglos xx y xix el concepto de familia española ha evolucionado rápidamente, permitiendo a aquellas que se consideran no tradicionales adquirir derechos que antes no se tenían. Es por ello que consideramos de interés analizar los distintos tipos de relaciones familiares que se pueden establecer en España, y mencionar cómo pueden acceder a las TRA, en relación con el DGP. Es preciso tener en cuenta que el DGP se enmarca dentro de las TRA, y que nuestro enfoque se orienta hacia quién puede prestar el consentimiento y cómo se regula en el ordenamiento jurídico español esa prestación, según los distintos modelos familiares, aun en los casos en los que se produce una donación de material genéti$\mathrm{CO}^{25}$. Consideramos que puede resultar de interés, respecto al DGP, el análisis de

25 Realín Hernández, N., Macías Bestard, C., Realín Hernández, N., Machado Realín, S., Rodríguez Leyva, E., Díaz González, L. y Maynard Bermúdez, R. E., "La reproducción humana asistida como problema bioético" [en línea], Revista de Información Científica, n. ${ }^{\circ}$ 3, 2009, ıо, disponible en: http://www.revinfcientifica.sld.cu/index.php/ric/article/view/I 267/2537 [Consultado el 9 de diciembre de 2017]. 
los distintos modelos, para observar que la prestación del consentimiento no es igual en un tipo familiar que en otro, teniendo en cuenta la regulación española.

A continuación se detallan los tipos de familia que reconoce la justicia, y junto a ellos se mencionan las principales leyes que los regulan, así como las normas que disciplinan el acceso a las técnicas de reproducción asistida:

a) Parejas de personas heterosexuales. Este tipo de familia está compuesta por la unión entre un hombre y una mujer.

En el artículo 6.3 de la Ley i4/2006, referente al consentimiento de fecundación, se menciona la necesidad de consentimiento del esposo para que la mujer se someta a una técnica de reproducción asistida, sea que se trate de una práctica homóloga o heteróloga. Es así como este modelo familiar queda reflejado dentro de la normativa sobre $\mathrm{TRA}^{26}$.

b) Parejas de personas homosexuales. En España estas familias están permitidas desde el año 2005. Pero además existe la posibilidad de que uno de los miembros de la pareja o ambos sean transexuales. España es uno de los países donde los derechos de los homosexuales cuentan con mayor reconocimiento.

De singular importancia resulta destacar la Ley I3/2005, de I de julio, por la que se modifica el código civil en materia de derecho a contraer matrimonio. Esta norma regula el matrimonio entre personas homosexuales, permitiendo que la unión de personas del mismo sexo se inscriba en el registro civil como matrimonio. Además se reconocieron otros derechos, como aquellos a la adopción, al divorcio o a la herencia ${ }^{27}$.

El artículo 6.3 de la Ley I4/2006, artículo sobre el consentimiento para la fecundación, regula la necesidad de autorización por parte de ambos miembros de la pareja a la hora de recurrir a una técnica de reproducción asistida; si bien se habla de "marido", se entiende que se refiere también a la mujer casada homosexual que no se somete a la fecundación ${ }^{28}$.

En el artículo 7·3 de la Ley i4/2006, en relación con la filiación, se contempla el registro de los dos miembros de la pareja como padres, para lo cual, aquella mujer que no sea la madre biológica, debe redactar un escrito manifestando su intención de adopción y entregarlo en el registro civil, antes del nacimiento.

26 Berrocal Lanzarot, A. I., "De nuevo sobre la reproducción humana asistida en España. Análisis jurídico-sanitario de la ley I4/2006, de 26 de mayo (i. ${ }^{a}$ parte)" [en línea], Revista de la Escuela de Medicina Legal, n. ${ }^{\circ}$ 9, 2008, 22-42, disponible en: https://revistas.ucm.es/index.php/REML/ article/view/50288/4674I [Consultado el 22 de septiembre de 20 I 7].

27 De la Fuente, M. L, "Ley I3/2005, de I de julio, por la que se modifica el código civil en materia de derecho a contraer matrimonio" [en línea], Foro. Revista de Ciencias furídicas y Sociales, nueva época, n. ${ }^{\circ}$ 2, 2005, 4I I-438, disponible en: http://revistas.ucm.es/index.php/Foro/ article/viewFile/foroo5052 I04I IA/I 3750 [Consultado el 22 de septiembre de 20I 7].

28 Lamm, E., "La importancia de la voluntad procreacional en la nueva categoría de filiación derivada de las técnicas de reproducción asistida" [en línea], Revista de Bioética y Derecho, n. ${ }^{\circ}{ }_{24}$, 201 2, 76-9I, disponible en: http://www.ub.edu/fildt/revista/RByD24_master.htm [Consultado el 25 de septiembre de 2017 ]. 
Esto también supone una carga adicional para los matrimonios entre personas homosexuales, puesto que los tradicionales no precisan de tal informe o petición.

Se habla de madres, ya que en España aquellos matrimonios formados por dos hombres no pueden recurrir a la gestación por sustitución (art. Io de la Ley I4/2006), aunque sí registrar a los hijos una vez se ha practicado fuera del país ${ }^{29}$.

c) Familias monoparentales. Este tipo de familia lo componen un padre o una madre de forma individual, y sus hijos. La ley actual permite a una mujer sin pareja acudir a una técnica de reproducción asistida, siendo ella la única titular de responsabilidad parental respecto de sus hijos. En este sentido los hombres se encuentran en desventaja ${ }^{3}$.

d) Parejas de hecho. La pareja de hecho es la unión entre dos personas, ya sean homosexuales o heterosexuales, no casadas. Es una alternativa al matrimonio que quedó regulada por la Ley $2 / 2003$.

El artículo 8.2 de la Ley I4/2006, sobre conformidad de paternidad, regula la atribución de la filiación del hijo biológico de un donante al miembro de la pareja que no se haya sometido a la fecundación. En las parejas de hecho, al contrario que en el matrimonio homosexual y heterosexual, si un miembro de la pareja decide someterse a una técnica de fecundación no necesita el consentimiento del otro.

\section{E. Elección de características y sexo del preembrión, y DGP}

Las nuevas técnicas de análisis con manipulación del genoma han permitido seleccionar aquellos genes más aptos, lo que permite crear individuos "perfectos". Lo anterior abre una nueva cuestión: en el campo de la genética, al igual que en otras materias científicas, ¿se debe crear todo lo que se puede? Es decir, teniendo la posibilidad de crear personas lo más genéticamente perfectas posible, ¿debemos hacerlo o, por el contrario, ello supone una vulneración ética y de los derechos humanos?

La bioética adquiere un papel primordial en las ciencias biológicas, en el momento en que el ser humano es capaz de intervenir en la creación, transcurso y muerte del ser humano.

Sabiendo que los embriones se verán sometidos a una criba en la cual solo los más aptos genéticamente pasarían, la bioética se cuestiona si constituye o no

29 Berrocal Lanzarot, A. I., "De nuevo sobre la reproducción humana asistida en España. Análisis jurídico-sanitario de la ley $\mathrm{I}_{4} / 2006$, de 26 de mayo (2. ${ }^{\mathrm{a}}$ parte)" [en línea], Revista de la Escuela de Medicina Legal, n. ${ }^{\circ}$ Io, 2009, 20-28, disponible en: https://revistas.ucm.es/index.php/REML/ article/view/50302/46755 [Consultado el 25 de septiembre de 201 7].

30 Jociles Rubio, M. I. y Villamil Pérez, F., "Madres solteras por elección: representaciones sobre la fecundación sexual como vía de acceso a la maternidad" [en línea], Chungará, n. ${ }^{\circ}$ 44(4), 20 I 2 , 7 I 7-73 I, disponible en: http://www.scielo.cl/pdf/chungara/v44n4/arti 2.pdf [Consultado el 24 de septiembre de 20I7]. 
una violación de la dignidad humana el excluir a aquellos que presentan peores características que sus semejantes, aunque estas sean solo ínfimas. Y otra cuestión es la de quién elige qué dotaciones son las más apropiadas para la vida del individuo.

El DGP no solo da la posibilidad de crear individuos libres de malformaciones genéticas, también permite crear embriones escogiendo sus rasgos físicos.

A contrario sensu, ¿sería ético no usar la tecnología a disposición para mejorar la calidad de vida? La cuestión de la eutanasia ha generado planteamientos sobre los límites de "la calidad de vida", es decir, respecto de si se debe considerar aceptable la muerte de una persona, en este caso embrión, sabiendo que la calidad de vida que tendrá será ínfima. Se ha planteado que la defensa de la vida, en casos críticos, puede llegar a ser inmoral; esta opción se debería realizar teniendo en cuenta valores espirituales y morales, ya que este "sufrimiento" también puede constituir una violación de la dignidad humana ${ }^{3 \mathrm{I}}$.

$\mathrm{Al}$ ponerse en cuestión la integridad humana, la dignidad y los derechos, la justicia ha tenido que regular estas cuestiones, poniendo unos límites y dotando a la ética de una herramienta idónea para acotar aquellos actos que superen los límites de la moralidad.

La práctica de esta selección puede constituir una vulneración de la dignidad y los derechos de los seres humanos, en primer lugar, por no permitir el derecho a la vida de ciertos embriones, los cuales han sido rechazados por sus características. $\mathrm{Y}$, ¿qué pasa con aquellos niños concebidos por métodos naturales?, ¿serán ciudadanos de segunda?, ¿tendrán las mismas oportunidades y competencias que alguien seleccionado antes de nacer?

La selección del sexo es un tema muy conflictivo; en primer lugar, hay que decir que el sexo del embrión se puede escoger por motivos de eutanasia negativa pero también positiva. En el caso de la negativa se escogerá el sexo del bebé en aquellos casos en que la enfermedad genética está ligada a un determinado cromosoma $\mathrm{X}$ o $\mathrm{Y}$, y no por motivaciones subjetivas ${ }^{32}$.

La elección del sexo mediante criterios ligados a la eugenesia positiva es más reprochable, ya que los padres escogen al embrión dependiendo del sexo que crean ellos que es mejor o más apropiado.

Existen dos motivos principales por los cuales escoger el genoma de un hijo: por motivos de salud, librándolo de ciertas enfermedades hereditarias, o por motivos de preferencia paterna. Tanto una forma de elección como la otra generan

3 I Malamud Herrera, S., "Diagnóstico genético preimplantatorio y eugenesia. Análisis éticojurídico" [en línea], Revista Colombiana de Bioética, 8(I), 2013, I23-I43, disponible en: http:// www.redalyc.org/articulo.oa? id=I89228429009 [Consultado el 23 de septiembre de 20I 7].

32 Casas Martínez, M. ${ }^{a}$ D. L., "Prejuicios, estereotipos y discriminación: reflexión ética y psicodinámica sobre la selección de sexo embrionario" [en línea], Acta Bioethica, I4(2), 2008, I48-i 56, disponible en: http://www.scielo.cl/scielo.php?pid=S I 726-569X2008000200004\&script=sci_ arttext [Consultado el 23 de septiembre de 2017 ]. 
controversias, es por ello que cada país debe fijar los límites éticos que estime oportunos; en el caso de España, la principal ley que regula esta práctica es la Ley I4/2006. La regulación sobre la elección de sexos aparece en el artículo 26 que prohíbe la elección del sexo del embrión.

A nivel europeo existen diferentes reglamentos sobre esta materia, uno de los principales, el ya citado Convenio de Oviedo, de I997, el cual se firmó con el acuerdo de 20 países, con el objeto de definir y consagrar unas pautas europeas sobre biomedicina y derechos humanos. Uno de los apartados clave sobre este tema es el artículo I4 del capítulo 4, en el cual se establece que no está permitido escoger el sexo del embrión, exceptuando aquellos casos que eviten una enfermedad grave (eugenesia negativa).

\section{F. El embrión y su consideración jurídica ante el DGP}

Un tema de gran importancia es la naturaleza jurídica del embrión, ya que los diferentes ordenamientos jurídicos no ofrecen un tratamiento unitario del mismo. La consideración del embrión como persona determina la prohibición del DGP, mientras que si se entiende que es el nacimiento el que determina la personalidad, como es el caso en el derecho español (arts. 29 y 30 c.c.), la práctica del DGP está permitida. Veamos con un poco más de detalle estas dos posturas, claramente enfrentadas.

La bioética del embrión trata de aclarar cuál es su identidad, si tiene personalidad jurídica propia y qué destinación le podemos dar: ¿qué es?, ¿tiene derechos?, ¿es una simple muestra de laboratorio?, etc. 33 .

A medida que han ido avanzando las técnicas de reproducción, lo han hecho también las leyes que las regulan; esto ha sido posible gracias a los planteamientos éticos sobre el embrión, los cuales han relevado la cuestión de que, si un embrión por su naturaleza se puede considerar humano o prototipo de este, estaríamos ante un sujeto con derechos y dignidad.

Existen diferentes opiniones sobre la identidad del embrión y su protección judicial34:

a. Personalidad jurídica previa al nacimiento:

Esta doctrina le atribuye al embrión la categoría de persona, incluso antes de nacer, y por tanto le reconoce personalidad jurídica. Existen controversias entre sus defensores sobre el momento en que se debe dotar al embrión de este derecho: al nacer, o en el momento de la unión del ovulo y el espermatozoide, o en la fase de anidación.

33 Guillem-Tatay Pérez, D., "El estatuto jurídico del embrión humano", Revista furídica de la Comunidad Valenciana: jurisprudencia seleccionada de la Comunidad Valenciana, n. ${ }^{\circ}$ 24, 2007, 5-i 6.

34 Guillem-Tatay Pérez, "El estatuto jurídico del embrión humano”, cit., 5-i6. 
Se trata de la protección jurídica al concebido y de la discusión doctrinal sobre la tutela del artículo i 5 de la Constitución española a los embriones in vitro mediante TRA, lo que enlaza directamente con la experimentación humana 35. Para esta doctrina la controversia radica en la calificación como "humano" que se le confiere al embrión, desde una visión católico-cristiana, considerándolo como persona desde la concepción y rechazando cualquier intervención en el ámbito genético ${ }^{36}$.

b. Personalidad incompleta del embrión:

Esta teoría defiende que no es posible dotar de los mismos derechos y personalidad jurídica a un nacido que a un embrión, pero que aun así se le debe reconocer un grado de personalidad, ya que es considerado como el origen del ser humano, y por tanto se debe proteger. Pero también hay que tener en cuenta que existe la posibilidad de que el embrión no llegue a formarse, o nazca incapaz. Por lo que esta teoría considera al embrión como un prototipo de ser humano, que hay que proteger y respetar, pero no en el mismo grado que al ser humano ya nacido.

c. El embrión no posee personalidad jurídica:

La premisa de sus defensores es que el embrión no es una persona, y por tanto no se le puede atribuir ningún derecho. Opinan que las demás teorías defienden al embrión por lo que será en el futuro, no por lo que es en el presente. El embrión, por tanto, es propiedad de los progenitores, quienes podrán disponer de él como de cualquier otra parte de su propio cuerpo ${ }^{37}$. Quienes rechazan la caracterización del embrión como persona, opinan que para ser persona es necesario tener "autoconciencia, sentido moral y racionalidad", y el embrión carece de todos ellos ${ }^{3}$.

Pero, ¿quién tiene la última palabra sobre qué es el embrión? Hay quien cree que la ciencia debe ser quien acredite qué es, pero lo cierto es, como ya hemos visto, que en esta decisión entran otros factores como los éticos, los humanos,

35 Verda y Beamonte, J. R. D., "La protección jurídica del concebido en el derecho español" [en linea], Revista Boliviana de Derecho, n. ${ }^{\circ}$ 22, 2016, 20, disponible en: http://revista-rbd.com/articulos/20r6/r6-33.pdf [Consultado el 9 de diciembre de 201 7 ].

36 Jiménez González, J., "Marco legal internacional y conflicto ético del diagnóstico genético preimplantacional y las nuevas técnicas de donación mitocondrial" [en línea], Ius et Scientia, n. ${ }^{\circ}$ 2, 20г6, 207, disponible en: https://institucional.us.es/iusetscientia/index.php/ies/article/ view/70/43 [Consultado el 9 de diciembre de 201 7].

37 Moreno Cidre, Y., "Dilemas éticos en el asesoramiento genético del diagnóstico prenatal" [en línea], Bioética, n. ${ }^{\circ}$ 3 I, 2008, Io-I 7, disponible en: http://www.cbioetica.org/revista/8 I/8 I I I 7 . pdf [Consultado el 24 de septiembre de 20I7].

38 Busquets Alibés, E., Abel Fabre, F., Craven-Bartle, J., Ferrer Salvans, P., Nogués Carulla, R. M., Terribas Alamego, J. y Terribas Sala, N., "Consideraciones sobre el embrión humano" [en línea], Bioètica y Debat, n. ${ }^{\circ}$ I 5, 2009, I-I 2, disponible en: http://www.raco.cat/index.php/ BioeticaDebat_es/article/viewFile/259306/346526 [Consultado el 24 de septiembre de 20I7]. 
los religiosos, etc. En la bioética confluyen todos estos puntos de vista, lo cual ha ayudado en el proceso de creación de las leyes que regulan estas prácticas.

Así, la Ley I 4/2007 considera al embrión humano antes de ser depositado en el útero como "preembrión”, por lo tanto, sin protección jurídica. Pero existen discrepancias ante esta desprotección y clasificación entre embrión y preembrión. Ya que científicamente no se puede considerar a un embrión, aunque no se encuentre dentro del útero materno, como algo semejante a los dos gametos que lo forman, puesto que en el momento de fraguarse la unión se genera un organismo independiente formado por 46 cromosomas.

La doctrina se ha pronunciado expresamente sobre la manera de resolver el derecho español este supuesto, teniendo en cuenta, además, la postura del Tribunal Constitucional ${ }^{39}$. El asunto es determinar si las parejas o la mujer que acude de forma individual a las TRA pueden decidir la descongelación de los embriones, y definir su encaje constitucional. Hay que tener en cuenta que el alto tribunal se refiere al nasciturus que se encuentra en el útero materno, por lo que parece dejar fuera al embrión no transferido. Sin embargo, la doctrina considera que, como en las TRA media un tiempo entre concepción y gestación, la postura del Tribunal se refiere a la procreación natural, pero que es aplicable a las TRA por cuanto considera que el embrión existe con individualidad propia y no comienza su vida con la transferencia al útero, sino en un momento anterior.

La ley, además, impide crear embriones con otros fines que no sean el de la fecundación; es decir, no está permitida la fabricación de embriones destinados a la investigación en el laboratorio, como objeto de muestra o de estudio. Esta prohibición también está contemplada en el artículo i 8 del Convenio de Oviedo.

Por su parte, la Ley I 4/2006 sigue la misma línea. En ella, como ya se ha comentado, se contempla en el artículo i 5 la utilización de embriones con fines de investigación, siempre y cuando haya consentimiento y el tiempo de desarrollo del embrión no supere los 14 días. De modo que se permite su uso, pero teniendo presentes los límites de la ética, puesto que a medida que evoluciona embrión, va adquiriendo características fisiológicas humanas.

En cuanto a la técnica de DGP, surge la problemática sobre la manipulación y selección de embriones desechando muchos otros, de manera que para realizar este diagnóstico se precisa de la obtención de un mayor número de preembriones, aunque finalmente solo se implanten 3 .

Finalmente, la ley contempla la igualdad de derechos de los embriones crioconservados con anterioridad, esto en la Disposición adicional primera. Problema ético muy criticado de la anterior Ley de 45/2003, de 2 I de noviembre,

39 Verda y Beamonte, "La protección jurídica del concebido en el derecho español", cit., 22-23. Cfr. López Guzmán, J., "Diagnóstico genético preimplantatorio (DGP)”, en Zurriaráin, R. G. (coord.), La desprotección del no nacido en el siglo XXI, Madrid, Ediciones Internacionales Universitarias, 201 2, 89-107. 
por la que se modifica la Ley 35/1988, de 22 de noviembre, sobre Técnicas de Reproducción Asistida, en la que los embriones creados antes de entrar en vigor aquella seguían una normativa diferente.

Los usos del embrión más denunciados, y que suscitan mayor debate, son los comentados en los siguientes puntos ${ }^{4}$.

Uno de los planteamientos más controvertidos es si se puede utilizar un embrión como un simple objeto de análisis, o si se debe tratar como algo más que una muestra de laboratorio, sabiendo que puede llegar a ser una persona. Esta cuestión es muy importante pues, dependiendo de lo que entendamos por embrión, podríamos estar ante un acto anticonstitucional, atentando contra la dignidad humana.

La Ley I4/2006 establece en su artículo I 3 que las intervenciones terapéuticas en el preembrión solo pueden realizarse para tratar o evitar la transmisión de una enfermedad, con evidencia suficiente de su posibilidad de mejora. Lo que limita, en cierto modo, las prácticas a realizar en el embrión. Además, se prohíbe la modificación de genes y la manipulación fuera de centros sanitarios autorizados y por equipos cualificados. Cualquier práctica con embriones deberá estar acreditada por la CNRHA, por lo que se regula el control de cualquier proceso o manipulación sobre el embrión, evitando metodologías que puedan dañarlo.

Por otra parte, en lo referente a la utilización del embrión como material de investigación, de acuerdo con el artículo I 5 , también se requiere de un centro especializado para la manipulación, y de la autorización previa por la CNRHA, con lo que se intenta garantizar los derechos del preembrión, si bien es cierto que estos no se pueden comparar con los de un ser completo.

\section{G. El DGP extensivo}

Esta cuestión está muy ligada a la anterior, ya que el conflicto en este caso se produce cuando el embrión es utilizado como una herramienta o material para ayudar a terceras personas que son compatibles con su material genético. $\mathrm{Mu}-$ chos son los que se preguntan si es ético crear a un ser humano solo porque se necesite para un fin, convirtiéndose este en un medio o terapia para otro; es lo que se denomina "bebé medicamento". La realización del procedimiento pone de manifiesto ciertas cuestiones, como el interés superior del niño a nacer, la reducción de la diversidad genética o la destrucción de embriones. No obstante, la principal ventaja es la posibilidad de salvar una vida que además es la de un familiar, prevaleciendo el principio de solidaridad ${ }^{4}$.

40 Abellán, F., "Aspectos bioéticos y legales del diagnóstico genético preimplantatorio (DGP)" [en línea], Revista de la Escuela de Medicina Legal, n. ${ }^{\circ}$ 3, 2006, I-I3, disponible en: https://revistas. ucm.es/index.php/REML/article/view/50206/46658 [Consultado el 25 de septiembre de 2017].

4i García Moyano, L. M., Pellicer García, B., Buil Tricas, B., Juárez Vela, R., Guerrero Portillo, S. y Antón Solanas, I., “Análisis bioético de la generación de ‘bebés medicamento”" [en 
Este tipo de terapia aparece establecido en el artículo i 2.2 de la Ley I4/2006 pero no se contemplaba en las leyes anteriormente promulgadas, y precisa de informe favorable de la CNRHA.

En este supuesto la selección de embriones se realiza para escoger los que sean compatibles con la persona que se pretende curar, normalmente un hermano. Estos "bebés medicamento" fungen como donantes de células para lograr la curación. La polémica del DGP extensivo gira en torno a la instrumentalización del concebido para ser donante y curar, por lo que se contemplan distintas posturas: la considerada por la filosofía y la ética de que el hombre no es un instrumento, sino un fin en sí mismo; y las religiosas que consideran el embrión como ser humano, y que tratamos en otro punto del presente trabajo.

\section{H. DGP y eugenesia}

En la actualidad, el término eugenesia viene asociado al DGP y a los nuevos métodos de fecundación, como puede ser la fecundación in vitro, la cual, al igual que otras técnicas de fertilidad, comenzó con la intención de dotar a padres estériles de un hijo, pero hoy en día cada vez más se centra en que la fecundación se realice escogiendo el embrión de mejor calidad, y cuyas cualidades cumplan las exigencias de los padres ${ }^{42}$.

La eugenesia es la disciplina que busca la mejora y conservación de los genes humanos, y el DGP se ha convertido en la mejor herramienta para lograrlo. Existen dos tipos de eugenesia asociada con el diagnóstico genético preimplantacional, la positiva y la negativa:

- La eugenesia negativa, que se asocia con el diagnóstico preventivo, el cual se encarga de evitar la transmisión genética de enfermedades graves. Este tipo de eugenesia es la menos conflictiva ya que no consiste en la elección paterna de determinadas características del embrión, simplemente se encarga de escoger aquellos embriones que no contengan una enfermedad grave. Es decir, esta técnica lo que hace es excluir a aquellos embriones con malformaciones, pero no escoge a aquellos embriones que contengan un cúmulo de características buscadas 43 .

- La eugenesia positiva, que se asocia con el diagnóstico perfectivo, el cual busca escoger a aquel embrión que contenga ciertas cualidades tanto físicas como conductuales en los genomas. Es decir, no solo se desechan enfermedades,

línea], Revista de Bioética y Derecho, n. ${ }^{\circ}$ 36, 2016, 55-65, disponible en: http://revistes.ub.edu/ index.php/RBD/article/view/I 5376/I 8574 [Consultado el 25 de septiembre de 20I 7 ].

42 Andorno, R., "Derecho frente a la nueva eugenesia: la selección de embriones in vitro" [en línea], Revista Chilena de Derecho, n. ${ }^{\circ}$ I, I994, 32 I-328, disponible en: http://www.jstor.org/ stable/4r609293? ?seq=i\#page_scan_tab_contents [Consultado el 23 de septiembre de 2017 ].

43 Collazo Chao, E., "Problemas éticos en la selección de embriones con finalidad terapéutica" [en línea], Cuadernos de Bioética, 2 I (2), 2010,23 I-242, disponible en: http://aebioetica.org/revistas/2010/2 I/2/72/23I.pdf [Consultado el 23 de septiembre de 2017 ]. 
también se escogen los embriones en función de aquellas "cualidades a la carta" que resultan más deseables para los padres. Esta técnica es la más polémica ya que se crean niños "a la moda", o al gusto de los padres; no es que se descarten determinados embriones por tener una enfermedad, sino que se prefieren unos que sean de una determinada manera, no permitiendo al azar escoger cualquier hijo para ellos 44 .

\section{Breve mención a la normativa aplicable al DGP en algunos países europeos}

Este apartado se centra en un breve estudio comparativo de la normativa aplicable al DGP dentro de la Unión Europea. Así, se expone la legislación de algunos países europeos a fin de ilustrar con ejemplos los diferentes modos de tratar una misma realidad en función de consideraciones éticas, culturales o sociales, así como de los gobiernos de los Estados ${ }^{45}$.

\section{A. Portugal}

En Portugal la normativa que regula el proceso de DGP es la Ley n. ${ }^{\circ} 32 / 2006$, de 26 de julio, de procreación medicamente asistida.

Como indica el nombre, la ley no solo se centra a los casos de infertilidad, sino que también plantea el tratamiento de enfermedades de origen genético u otras y el tratamiento para la obtención de un embrión con un grupo HLA determinado. El capítulo $\mathrm{v}$ dispone lo referente a la normativa aplicable al DGP y otros temas relacionados, como la prohibición de elección del sexo, descrita en el artículo 7, la investigación con embriones, en el artículo 9, y la necesidad de consentimiento y confidencialidad, en los artículos I4 y i 5 respectivamente.

La legislación portuguesa aprueba el procedimiento DGP, incluyendo también el DGP a terceros, que estará regularizado en cada caso por el Conselho Nacional de Procriação Médicamente Assistida (Consejo Nacional de Procreación Médicamente Asistida), creado a partir del capítulo vi de la citada ley.

El Consejo Nacional de Ética advierte como relevante el criterio de selección del embrión y el destino de los no seleccionados.

Su última modificación se contempla en Ley 25/20r6 de 22 de agosto, que regula el acceso a la gestación por sustitución, procediendo a la tercera modificación de la Ley 32/2006, de 26 de julio, por la que se regulan las condiciones de aplicación y se contempla el derecho a la gestación por sustitución.

45 Abellán, "Aspectos bioéticos y legales del diagnóstico genético preimplantatorio (DGP)”, cit., 8. 


\section{B. Reino Unido}

La legislación británica en términos de RA es muy extensa y compleja, ya que genera multitud de divisiones en diferentes leyes interconectadas entre sí, lo que dificulta su estudio y entendimiento. No obstante, la Human Fertilisation and Embriology Act, I990 (Ley sobre Fertilización Humana y Embriología, I990), y posteriormente la Human Fertilisation and Embriology Act, 2008 (Ley sobre Fertilización Humana y Embriología, 2008), que deroga la anterior y se encuentra vigente, se crearon como herramienta legislativa en lo relativo a RA.

En cuanto al DGP, está permitido en el Reino Unido, y la Human Fertilisation and Embryology Authority (HFEA, Autoridad en Fertilización y Embriología) se encuentra regulando su uso. Además, la normativa británica también contempla, en casos concretos, el uso de embriones humanos en investigación siempre que no superen los I4 días de desarrollo. Esta legislación es bastante permisiva y elabora una base de datos con las enfermedades que se pueden evitar con el DGP.

\section{Francia}

Las disposiciones con respecto al DGP en Francia se contemplan en el Code de la santé publique (código de salud pública), específicamente en la Ley 2004-800, de 6 de agosto de 2004, relativa a la bioética).

El uso del DGP en Francia es restringido, puesto que para realizarlo se precisa de un médico que certifique la alta probabilidad de tener un hijo que presente una enfermedad genética incurable en el momento del diagnóstico. Además, solo se podrá comprobar la anomalía que se prevé va a poseer debido a sus progenitores. Por tanto, vemos que es más restrictiva, y exige la existencia de una enfermedad genética previamente identificada en alguno de los dos progenitores, y que hayan convivido durante un periodo mínimo de dos años. Estas disposiciones se contemplan en el artículo L2 I 3 I-4 del Code de la santé publique. En el caso de DGP-HLA, precisa de claras mejoras para la enfermedad del ya nacido y la integridad del futuro nacido.

\section{Italia}

La Ley de 19 de febrero de 2004, . $^{\circ}$ 40, Norme in materia di procreazione medicalmente assistita (Normas en materia de procreación médicamente asistida), regula en su artículo I 3 lo referido a las prácticas en embriones humanos y por tanto se incluye el DGP dentro de ellas.

En Italia el DGP está prohibido por considerarse una técnica de selección eugenésica, siendo una de las más restrictivas leyes europeas en cuanto a TRA se refiere. 
La importante restricción propició que en 2005 se realizase un referéndum debido a las críticas populares y atendiendo a cuatro aspectos: permitir la investigación en células madre embrionarias, permitir la generación de más de tres embriones por ciclo de RA y su posterior criopreservación, permitir el DGP en casos médicamente indicados y, por último, permitir la donación de gametos. Finalmente, el referéndum fue declarado inválido por no alcanzar el umbral electoral.

En este punto corresponde mostrar la doctrina del Tribunal Europeo de Derechos Humanos, que se ha referido de forma expresa a esta cuestión ${ }^{46}$.

En Italia, la legislación solo permitía el acceso a las TRA a las parejas estériles o infértiles, no pudiéndose realizar el DGP en ningún otro supuesto, por lo que en el caso Costa y Pavan c. Italia (asunto 54270/ro, Sec. $2^{\mathrm{a}}$., de 28 de agosto de 20I2) el Tribunal Europeo utiliza el criterio de la coherencia externa. En este caso la única opción para la pareja era el DGP, con la finalidad de que el hijo no tuviera la enfermedad; el Tribunal Europeo se pronuncia y considera incoherente la legislación italiana, ya que conduce a una interferencia desproporcionada en la vida de los sujetos. Esto entra en relación con lo que dispone el artículo 8 del Convenio para la Protección de los Derechos Humanos y de las Libertades Fundamentales, respecto al derecho al respeto a la vida privada y familiar, por lo que el Tribunal abogó por el derecho de los padres a tener un hijo libre de la enfermedad transmisible hereditariamente y a la utilizar el DGP para salvar dicha circunstancia.

\section{Conclusiones}

Desde su primera aplicación en humanos en I990, el DGP se ha desarrollado como herramienta para seleccionar embriones según su constitución genética y descartar aquellos que no se ajusten a los patrones requeridos por el hecho de poseer alteraciones relacionadas con ciertas enfermedades que han sido comprobadas. Impedir la transferencia de los embriones probados como enfermos evita que el nacido desarrolle la patología, en favor de un nacimiento libre de esa carga genética. Del mismo modo, el DGP es una técnica que cuenta con una gran fiabilidad y rapidez en cuanto a los análisis diagnósticos, características que lo hacen consolidarse en el campo de la reproducción humana asistida.

46 Puede verse, sobre la postura del Tribunal Europeo de Derechos Humanos, la aportación de Corn, E., "La reproducción humana asistida en Italia. Presente y futuro después de la derogación de la prohibición de fecundación heteróloga" [en línea], Bioética y Derecho, n. ${ }^{\circ} 35,2015$, I 8-3 I, disponible en: http://www.redalyc.org/pdf/783/7834I437003.pdf [Consultado el 9 de diciembre de 2017]. Y la de Farnós Amorós, E., "La reproducción asistida ante el Tribunal Europeo de Derechos Humanos: de Evans c. Reino Unido a Parrillo c. Italia" [en línea], Revista Bioética y Derecho, n. ${ }^{\circ}$ 36, 20I6, 93-I I I, disponible en: http://scielo.isciii.es/pdf/bioetica/n36/ bioetica_tribunal.pdf [Consultado el 9 de diciembre de 2017]. 
El proceso de diagnóstico comporta una metodología compleja: los primeros pasos necesarios para efectuar un DGP son la obtención de gametos para fecundación mediante FIV o ICSI y la biopsia embrionaria a fin de obtener el material biológico para analizar. Tras conseguir las células del embrión se someterán al análisis genético que podrá realizarse mediante diferentes tecnologías dependiendo del paciente. Estas son: FISH, PCR y acGH. Una vez estudiadas las regiones del ADN, y seleccionados aquellos embriones sin afección de las características testadas, se procederá a la transferencia a útero para lograr un embarazo o se crioconservarán para posteriores usos.

El DGP se encuentra recomendado para determinadas circunstancias, entre las que encontramos: anomalías cromosómicas numéricas o estructurales, enfermedades ligadas a cromosomas sexuales, enfermedades monogénicas, enfermedades hereditarias de surgimiento tardío, madres con edad avanzada, padres con meiosis masculina alterada, fallos en implantación, abortos reiterados y con fines terapéuticos a favor de terceros.

En la actualidad es la Ley I4/2006 la que legisla sobre técnicas de reproducción asistida y por tanto la que regula el DGP. Pero, antes de la entrada en vigor de esta ley, otras fueron promulgadas sobre las TRA: la Ley 35/1988 y su modificación por la Ley 45/2003. Además, este tipo de técnicas promueven la creación de un gran número de leyes, lo que hace pensar en el elevado impacto de la reproducción asistida sobre la sociedad.

Este impacto sociológico conlleva la adopción de posturas éticas a favor y en contra de las prácticas llevadas a cabo, que al mismo tiempo retroalimentan la necesidad de cambio y de evolución tanto de la legislación como de la metodología. En el caso específico del DGP, el debate ético-legal está muy presente, al ser una técnica en pleno auge que ha evolucionado en los últimos años, debido a los grandes avances que ha traído consigo.

Las principales confrontaciones éticas que cabe señalar son las derivadas de la selección de embriones, la desestimación de los mismos, la obtención de embriones HLA compatibles para tratar enfermedades de otros individuos, la elección de las características deseadas y la posibilidad de usar la técnica para fines no terapéuticos. Otros planteamientos éticos derivados de las TRA también implican al DGP, como la preservación de datos confidenciales, especialmente los genéticos analizados por esta técnica, la necesidad de consentimiento informado y el acceso por diferentes tipos de familia.

Pese a estas controversias, la normativa española vigente solventa de manera eficiente estos posibles problemas. Incluso posee una Comisión Nacional de Reproducción Humana Asistida dedicada a asesorar, orientar actualizar y difundir los conocimientos científico-técnicos de las TRA y de los centros donde se realizan. Actualmente, el ordenamiento español es uno de los más permisivos a nivel europeo en términos de TRA. 
El análisis de ciertas legislaciones europeas hace visible la falta de coordinación existente entre los países miembros, lo que lleva en muchas ocasiones al turismo reproductivo hacia países donde se permita. Sería conveniente llegar a una normativa unificada en el ámbito internacional en torno al DGP, ya que hay muchas disparidades en la legislación analizada, lo que determina una inseguridad jurídica altamente criticable 47 .

Finalmente, cabe concluir que el DGP es una técnica muy valiosa, que ha supuesto una mejora en la esperanza de algunos padres de llegar a serlo, o de poder serlo sin transmitir su herencia genética cuando ello pueda comportar un perjuicio para la descendencia; y pese a las controversias que suscita, tiene una elevada aplicación en RA. Tal vez uno de los principales aspectos que es preciso mejorar sea el desarrollo de una legislación común para que todas las personas puedan acceder a la misma tecnología para su bienestar y el de sus familiares. Del mismo modo, se hace necesaria la creación de un comité que regule el DGP, puesto que los avances científicos se adelantan a los legislativos y hay que adaptarse a los nuevos descubrimientos lo antes posible, para evitar que no se pueda realizar un procedimiento porque la ley no lo contempla.

\section{Bibliografía}

Abellán, F., "Aspectos bioéticos y legales del diagnóstico genético preimplantatorio (DGP)" [en línea], Revista de la Escuela de Medicina Legal, n. ${ }^{\circ}$, 2006, I-I3, disponible en: https://revistas.ucm.es/index.php/REML/article/ view/50206/46658 [Consultado el 25 de septiembre de 20I 7 ].

Andorno, R., "Derecho frente a la nueva eugenesia: la selección de embriones in vitro" [en línea], Revista Chilena de Derecho, n. ${ }^{\circ} 2$ I, I994, 32 I-328, disponible en: http://www.jstor.org/stable/4I609293?seq=i\#page_scan_tab_contents [Consultado el 23 de septiembre de 2017 ].

Asúa González, C. I., "Responsabilidad civil derivada del uso de técnicas de reproducción asistida”, en Díaz Martínez, A. (coord.), Régimen jurídico-privado de la reproducción asistida en España: el proceso legal de reformas, Madrid, Dykinson, 2006, I03-I 20.

Ballif, B. C., Kashork, C. D., Saleki, R., Rorem, E., Sundin, K., Bejuani, B. A. y Shaffer, L. G., "Detecting sex chromosome anomalies and common

47 Jiménez GonzÁlez, J., “¿Es necesario un acuerdo internacional en torno al diagnóstico genético preimplantacional (DGP)?”, [en línea], Bioderecho, n. ${ }^{\circ}$ I, 2014 , I-I4, disponible en: http://revistas. um.es/bioderecho/article/view/20944I/r673 I I [Consultado el 9 de diciembre de 20 I 7]. 
triploidies in products of conception by array-based comparative genomic hybridization", Prenatal Diagnosis, 26(4), 2006, 333-339.

Bell, K. A., Van Deerlin, P. G., Feinberg, R. F., Du Manoir, S. y Haddad, B. R., "Diagnosis of aneuploidy in archival, paraffin-embedded pregnancy-loss tissues by comparative genomic hybridization" [en línea], Fertility and Sterility, 75(2), 200I, 374-379, disponible en: http://www.fertstert.org/article/ Soo I 5-O282(Oo)or 703-9/pdf [Consultado el ig de septiembre de 201 7].

Berrocal Lanzarot, A. I., "De nuevo sobre la reproducción humana asistida en España. Análisis jurídico-sanitario de la ley I4/2006, de 26 de mayo (I. ${ }^{a}$ parte)" [en línea], Revista de la Escuela de Medicina Legal, n. ${ }^{\circ}$ 9, 2008, 22-42, disponible en: https://revistas.ucm.es/index.php/REML/article/view/50288/ 4674I [Consultado el 22 de septiembre de 2017 ].

Berrocal Lanzarot, A. I., "De nuevo sobre la reproducción humana asistida en España. Análisis jurídico-sanitario de la ley I4/2006, de 26 de mayo (2. parte)" [en línea], Revista de la Escuela de Medicina Legal, n. ${ }^{\circ}$ Io, 2009, 20-28, disponible en: https://revistas.ucm.es/index.php/REML/article/view/50302/ 46755 [Consultado el 25 de septiembre de 20 I 7 ].

Boada, M., "La reproducción asistida. Problemática actual”, Revista de Debate Político, Fundación Rafael Campalans, n. ${ }^{\circ}$ 9, 2004, I-9.

Casas Martínez, M. a d. 1. L., "Prejuicios, estereotipos y discriminación: reflexión ética y psicodinámica sobre la selección de sexo embrionario" [en línea], Acta Bioethica, I4(2), 2008, I48-I 56, disponible en: http://www.scielo.cl/scielo.php?pid=S I 726-569X2008000200004\&script=sci_arttext [Consultado el 23 de septiembre de 2017 ].

Collazo Chao, E., "Problemas éticos en la selección de embriones con finalidad terapéutica" [en línea], Cuadernos de Bioética, 2 I (2), 2010,23 I-242, disponible en: http://aebioetica.org/revistas/2010/2 I/2/72/23 I.pdf [Consultado el 23 de septiembre de 20I7].

Conn, E., "La reproducción humana asistida en Italia. Presente y futuro después de la derogación de la prohibición de fecundación heteróloga" [en línea], Revista de Bioética y Derecho, n. ${ }^{\circ}$ 35, 20 I 5, I 8-3 I, disponible en: http://www.redalyc.org/pdf/783/7834I437003.pdf [Consultado el 9 de diciembre de 2017 ].

Busquets Alibés, E., Abel Fabre, F., Craven-Bartle, J., Ferrer Salvans, P., Nogués Carulla, R. M., Terribas Alamego, J. y Terribas Sala, N., “Conside- 
raciones sobre el embrión humano" [en línea], Bioètica y Debat, n. ${ }^{\text {I }} 5,2009$, I-I 2, disponible en: http://www.raco.cat/index.php/BioeticaDebat_es/article/viewFile/259306/346526 [Consultado el 24 de septiembre de 20I 7].

Casado, M., "Reproducción humana asistida: los problemas que suscita desde la bioética y el derecho" [en línea], Papers: Revista de Sociología, n. ${ }^{\text {53 }}$, I997, 37-44, disponible en: http://papers.uab.cat/article/view/v53-casado/pdf-es [Consultado el 25 de septiembre de 2017 ].

Cheng, L., Zhang, S., Wang, L., Maclennan, G. T. y Davidson, D. D., "Fluorescence in situ hybridization in surgical pathology: Principles and applications" [en línea], The Fournal of Pathology: Clinical Research, n. ${ }^{\circ}$ 3, 2017 , 73-99, disponible en: http://onlinelibrary.wiley.com/doi/ıo.rooz/cjpz.64/ epdf [Consultado el is de septiembre de 2017].

De la Fuente, M. L., "Ley I3/2005, de I de julio, por la que se modifica el código civil en materia de derecho a contraer matrimonio" [en línea], Foro. Revista de Ciencias Furídicas y Sociales, nueva época, n. ${ }^{\circ}$ 2, 2005, 4I I-438, disponible en: http://revistas.ucm.es/index.php/Foro/article/viewFile/FoROO5052 IO4IIA/I 3750 [Consultado el 22 de septiembre de 20I 7].

Díaz Martínez, A., "Responsabilidad por daños en la aplicación de técnicas de reproducción asistida: diferencias con la investigación biomédica (a propósito de las ssts de 23 de octubre de 2008 y 20 de noviembre de 2009)" (en línea], Revista de Derecho y Genoma Humano, n. ${ }^{32}$, 2010, 193-2 I8, disponible en: https://mega.nz/\#!SdklebLr!consys4e6rlGFkqxhWGgLGPoZagJk gR_LUk3 of 5 gNlA [Consultado el 8 de diciembre de 20I7].

Díaz Martínez, A. G., Valdés Abreu, M. D. l. C. y Dalmau Díaz, A., "Antecedentes y actualidades en el diagnóstico prenatal" [en línea], Revista Cubana de Obstetricia y Ginecología, 23(I), I997, 25-30, disponible en: http://scielo.sld. cu/scielo.php?script=sci_arttext\&pid=So I $38-600 X$ I 997000 I $00005 \& \operatorname{lng}=e s$ \&nrm=iso\&tlng=es [Consultado el 25 de septiembre de 20 I 7 ].

Díaz de Terán Velasco, M. C., "El diagnóstico preimplantatorio en la ley 35/1988, de 22 noviembre, sobre técnicas de reproducción asistida" [en línea], Derecho y Salud, n. ${ }^{\circ}$ I I, 2003, 73-84, disponible en: http://dadun. unav.edu/bitstream/ı I 7 I/I 3428/ı/diazdet_diagnos_preimplantatorio.pdf [Consultado el 25 de septiembre de 2017 ].

Enguer Gosálbez, P. y Ramón Fernández, F., "Dilemas bioéticos y jurídicos de la reproducción asistida en la sociedad actual en España” [en línea], Revista 
Latinoamericana de Bioética, n. ${ }^{\circ}$ 34, 2018 , disponible en: https://revistas.unimilitar.edu.co/index.php/rlbi/article/view/3 I 60 [Consultado el 7 de diciembre de 20I8].

FArnós Amorós, E., "La reproducción asistida ante el Tribunal Europeo de Derechos Humanos: de Evans c. Reino Unido a Parrillo c. Italia" [en línea], Revista Bioética y Derecho, n. ${ }^{\circ}$ 36, 20I6, 93-I I I, disponible en: http://scielo.isciii. es/pdf/bioetica/n36/bioetica_tribunal.pdf [Consultado el 9 de diciembre de 2OI 7 ].

Fernández González, M. ${ }^{a}$ B., "La responsabilidad civil del médico: su incidencia en las técnicas de reproducción asistida", Actualidad Civil, n. ${ }^{\circ}$ 4, I997, I073-IO88.

Gianaroli, L., Magli, M. C. y Ferrareti, A. P., "The in vivo and in vitro efficiency and efficacy of PGD for aneuploidy" [en línea], Molecular and Cellular Endocrinology, n. ${ }^{\circ}$ I 83, 200I, I 3-1 8, disponible en: http://www.sciencedirect. $\mathrm{com} /$ science/journal/03037207/I83/supp/SI? sdc=I [Consultado el $25 \mathrm{de}$ septiembre de 2017 ].

García Moyano, L. M., Pellicer García, B., Buil Tricas, B., Juárez Vela, R., Guerrero Portillo, S. y Antón Solanas, I., "Análisis bioético de la generación de 'bebés medicamento"' [en línea], Revista de Bioética y Derecho, n. ${ }_{3} 6$, 2ог6, 55-65, disponible en: http://revistes.ub.edu/index.php/RвD/article/ view/I 5376/I 8574 [Consultado el 25 de septiembre de 20 I 7 ].

Guillem-Tatay Pérez, D., "El estatuto jurídico del embrión humano", Revista Jurídica de la Comunidad Valenciana: jurisprudencia seleccionada de la Comunidad Valenciana, n. ${ }^{\text {2 } 24,2007, ~ 5-16 . ~}$

Handyside, A. H., Kontogianni, E. H., Hardy, K. y Winston, R. M. L., "Pregnancies from biopsied human preimplantation embryos sexed by Y-specific DNA amplification" [en línea], Nature, n. ${ }^{\circ} 344$, I990, 768-770, disponible en: https://www.nature.com/scitable/content/Pregnancies-from-biopsied-human-preimplantation-embryos-sexed-I I 575 [Consultado el 22 de septiembre de 2017 ].

Jiménez González, J., “¿Es necesario un acuerdo internacional en torno al diagnóstico genético preimplantacional (DGP)?”, [en línea], Bioderecho, n. ${ }^{\circ}$ I, 20I4, I-I4, disponible en: http://revistas.um.es/bioderecho/article/view/ 20944I/I673 I I [Consultado el 9 de diciembre de 20 I 7]. 
Jiménez GonZÁLez, J., "Marco legal internacional y conflicto ético del diagnóstico genético preimplantacional y las nuevas técnicas de donación mitocondrial" [en línea], Ius et Scientia, n. ${ }^{\circ}$ 2, 2016, 204-2 I4, disponible en: https:// institucional.us.es/iusetscientia/index.php/ies/article/view/7o/43 [Consultado el 9 de diciembre de 2017].

Jobanputra, V., Roy, K. K. y Kucheria, K., "Prenatal detection of aneuploidies using fluorescencein situ hybridization: A preliminary experience in an Indian set up" [en línea], fournal of Biosciences, 27 (2), 2002, I 55-163, disponible en: http://www.ias.ac.in/article/fulltext/jbsc/027/O2/Or 55-Or63 [Consultado el 25 de septiembre de 2017].

Jociles Rubio, M. I. y Villamil Pérez, F., "Madres solteras por elección: representaciones sobre la fecundación sexual como vía de acceso a la maternidad" [en línea], Chungará, 44(4), 20I 2, 7 I 7-73 I, disponible en: http://www.scielo. $\mathrm{cl} /$ pdf/chungara/v44n4/art 2 2.pdf [Consultado el 24 de septiembre de 2017].

Lamm, E., "La importancia de la voluntad procreacional en la nueva categoría de filiación derivada de las técnicas de reproducción asistida" [en línea], $R e-$ vista de Bioética y Derecho, n. ${ }^{\circ}$ 24, 201 2, 76-91, disponible en: http://www. ub.edu/fildt/revista/RByD24_master.htm [Consultado el 25 de septiembre de 2017 ].

López Guzmán, J., "Diagnóstico genético preimplantatorio (DGP)", en Zurriaráin, R. G. (coord.), La desprotección del no nacido en el siglo XXI, Madrid, Ediciones Internacionales Universitarias, 201 2, 89-107.

Lloveras N. y Sapena J., "El Diagnóstico Genético Preimplantacional” [en línea], Revista de Bioética y Derecho, n. ${ }^{\circ}$ I8, 2010, Iо-г6, disponible en: http:// revistes.ub.edu/index.php/RBD/article/view/798I/9883 [Consultado el $24 \mathrm{de}$ septiembre de 2017].

Malamud Herrera, S., "Diagnóstico genético preimplantatorio y eugenesia.Análisis ético-jurídico" [en línea], Revista Colombiana de Bioética, 8(I), 2013, I23I43, disponible en: http://www.redalyc.org/articulo.oa?id=I89228429009 [Consultado el 23 de septiembre de 2017].

Mastenbroek, S., Twisk, M., Van Echten-Arends, J., Sikkema-Raddatz, B., Korevaar, J. C., Verhoeve, H. R. et al., "In vitro fertilization with preimplantation genetic screening" [en línea], New England Journal of Medicine, 357(I), 2007, 9-17, disponible en: http://www.nejm.org/doi/full/ıo.1056/ NEJMOaO67744\#t=article [Consultado el 25 de septiembre de 20I 7 ]. 
Matorras, R. y Hernández, J. (eds.), Estudio y tratamiento de la pareja estéril: recomendaciones de la Sociedad Española de Fertilidad, con la colaboración de la Asociación Española para el Estudio de la Biología de la Reproducción, de la Asociación Española de Andrología y de la Sociedad Española de Contracepción [en línea], Madrid, 2007, 33 I-346, disponible en: http://www.sefertilidad.net/ docs/biblioteca/recomendaciones/completo.pdf [Consultado el 23 de septiembre de 20I 7 .

Mercado, C. A., Pedrueza, J. R. y García Ercoli, S. A., "dgr: técnica e indicaciones", Revista Médica Tucumán, I 5(I), 2010, 22-38.

Molina, I., Duque, C. C. y Alfonso, J., “Controversias legales en reproducción asistida humana", Revista Iberoamericana de Fertilidad, n. ${ }^{\circ}$ 23, 2006, 63-70.

Moreno Cidre, Y., "Dilemas éticos en el asesoramiento genético del diagnóstico prenatal" [en línea], Bioética, n. ${ }^{\circ}$ 3 I, 2008, IO- I 7, disponible en: http://www. cbioetica.org/revista/8I/8I ror 7.pdf [Consultado el 24 de septiembre de $2017]$.

Mori, M. ${ }^{a}$ D. L. A., Mansilla, E., García-Santiago, F., Vallespín, E., Palomares, M., Martín, R., Rodríguez, R., Martínez Payo, C., Gil Fournier, B., Ramiro, S., Lapunzina, P. y Nevado, J., "Diagnóstico prenatal y arrayhibridación genómica comparada ( $\mathrm{CGH})(\mathrm{I})$. Gestaciones de elevado riesgo" [en línea], Diagnóstico Prenatal, 23(2), 2012, 34-48, disponible en: http:// www.elsevier.es/es-revista-diagnostico-prenatal-32 7-articulo-diagnosticoprenatal-array-hibridacion-genomica-comparada-S2 I 734 I 27 I 2000339 [Consultado el ig de septiembre de 2017].

Muñoz-Núñez, M., Girón, J., Molina, L., Fernández, L., Velarde, P., Figueroa, M. J. y González, A., "Enfermedades hereditarias y técnicas de detección preimplantacionales” [en línea], Revista Iberoamericana de Fertilidad, n. ${ }^{\circ}$ 22, 2005, 343-359, disponible en: http://www.revistafertilidad.org/ Recursosweв/fertilidad/Fert-Sept-Octo5-Trabajo7.pdf [Consultado el 20 de septiembre de 2017$]$.

Pinto Andrade, C., "La responsabilidad civil médico sanitaria derivada de las Técnicas de Reproducción Asistida”, Revista Aranzadi de Derecho Patrimonial, n. ${ }^{\circ} 23,2009$, I $27-155$.

Ramos Fuentes, F. y Ribate Molina, M. ${ }^{\text {a }}$., "Diagnóstico genético preimplantacional" [en línea], Revista Española de Pediatría, n. ${ }^{\circ}$ 63(6), 2007, 443-499, 
disponible en: http://www.seinap.es/wp-content/uploads/Revista-de-Pediatria/2007/REP\% 2063-6.pdf [Consultado el 22 de septiembre de 2017].

Realín Hernández, N., Macías Bestard, C., Realín Hernández, N., Machado Realín, S., Rodríguez Leyva, E., Díaz González, L. y Maynard BerMÚDEZ, R. E., "La reproducción humana asistida como problema bioético" [en línea], Revista de Información Científica, n. ${ }^{\circ}$ 3, 2009, I-I 2, disponible en: http://www.revinfcientifica.sld.cu/index.php/ric/article/view/I 267/2537 [Consultado el 9 de diciembre de 2017].

Renwick, P. y Ogilvie, C. M., "Preimplantation genetic diagnosis for monogenic diseases: Overview and emerging issues" [en línea], Expert Review of Molecular Diagnostics, 7(I), 2007, 33-43, disponible en: http://www.tandfonline. com/doi/full/IO.I 586/14737159.7.I.33 [Consultado el ig de septiembre de 2017].

Rodríguez-Cadilla Ponce, M. D. R., "Consideraciones bioéticas y jurídicas de la información genética y el diagnóstico prenatal” [en línea], Vox furis, 28(2), 20I4, I5-40, disponible en: http://www.aulavirtualusmp.pe/ojs/index.php/ $\mathrm{VJ} /$ article/view/6/7 [Consultado el 25 de septiembre de 2017].

Scriven, P. N., Handyside, A. H. y Ogilvie, C. M., "Chromosome translocations: Segregation modes and strategies for preimplantation genetic diagnosis", Prenatal Diagnosis, I 8(I 3), I998, I437-I449.

Veiga, A., Santaló, J., Vidal, F., Calderón, G., Giménez C., Boada M., Egozcue J. y BARRI, P. N., "Twin pregnancy after preimplantation diagnosis for sex selection: Case report", Human Reproduction, n. ${ }^{\circ}$ 9, 1994, 2 I 5 6-2 159.

Verda y Beamonte, J. R. D., "La protección jurídica del concebido en el derecho español" [en línea], Revista Boliviana de Derecho, n. ${ }^{\circ} 22,2016$, I6-33, disponible en: http://revista-rbd.com/articulos/20r6/16-33.pdf [Consultado el 9 de diciembre de 20I7]. 